\title{
Developing information literacy skills in nursing and rehabilitation therapy students
}

\author{
Paola Durando and Patricia Oakley
}

\begin{abstract}
The environment in which nurses and rehabilitation therapists practice is rapidly evolving, resulting in changes in the skill sets and competencies required of new graduates. Evidence-based practice models, for example, require that entry-level nurses, physical therapists, and occupational therapists have the ability to identify, locate, and critically appraise research findings. This paper will describe curriculum-integrated, for-credit information literacy programs developed by the authors in collaboration with faculty members from the Schools of Nursing and Rehabilitation Therapy at Queen's University in Kingston, Ontario. The short-term goal of these programs is to teach undergraduate and graduate students advanced search strategy skills and critical appraisal techniques that will enable them to explore the implications of their literature findings. The long-term goal is to graduate practitioners who not only will have the skills to practice evidence-based health care but also will participate in scholarly activities and thus contribute to the evidence base in their disciplines.
\end{abstract}

\section{Introduction}

New Canadian educational directives for nursing and rehabilitation therapy place a much greater emphasis on critical enquiry and research. Information literacy standards developed by the library profession provide a ready framework for collaboration between librarians and professors [1]. Academic health sciences librarians, therefore, not only can, but also should, play a critical role in these new directives.

The Canadian Nurses Association states that the competencies required by new registered nurses to meet client needs will be most effectively and economically achieved through a baccalaureate education. A degree requirement for entry into nursing has been adopted throughout Canada by all provincial and territorial nurses' associations. The decision was adopted to reflect trends in health care in Canada and the changing role of nurses [1]. By 2010, a master's degree will be the minimum entry requirement to the professions of occupational therapy and physical therapy in Canada, running parallel to a worldwide movement to graduate studies. The professional master's degrees place more emphasis on research and on evidence-based and reflective practice [2].

Entry to Practice Competencies for Ontario Registered Nurses, produced as a guide to curriculum development and review, sets out the standards and competencies required for graduating nurses [1]. Professional standard 3 - application

P. Durando. Bracken Health Sciences Library, Botterell Hall, Queen's University, Kingston, ON K7L 3N6, Canada (e-mail: durandop@post.queensu.ca).

P. Oakley. National Research Council, Canada Institute for Scientific and Technical Information, Fredericton, NB

E3B 9W4, Canada (e-mail patricia.oakley@nrc-cnrc.gc.ca). of knowledge, lists the following competencies that are key to contributing to health or nursing research:

(i) identifying researchable questions

(ii) reading and critiquing research reports

(iii) using evidence-based knowledge from nursing, health sciences, and related disciplines to select and individualize nursing interventions

The National Physiotherapy Advisory Group states that the entry-level requirements for physiotherapists are changing because of the large growth of applicable information; the shift from institutional to community-based practice; more physiotherapists working independently and caring for patients with more acute, complex conditions; and the need to develop programs, make evidence-based decisions, and evaluate outcomes on an individual and program basis [3].

The Canadian Association of Occupational Therapists groups information literacy skills under the following professional accountability core competencies [4]:

(i) demonstrate ability to search for and obtain information

(ii) demonstrate ability to critically appraise the source and content of the information

(iii) apply new knowledge and relevant information to practice

The literature identifies a number of barriers to research utilization by practicing nurses. In one study, nurses identified the lack of searching skills and knowledge as well as critical appraisal skills [5]. The ability to locate and critically appraise research articles was the lowest-rated competency identified in a study addressing barriers to research utilization [6].

Welch found that although occupational therapists have positive feelings toward evidence-based practice, the recurring barriers are lack of time; staff shortages; deficits in information technology, literature searching, and research skills; inade- 
quate facilities; isolation from colleagues; and physicians who do not cooperate with change [7].

A study by Jette et al. of 488 members of the American Physical Therapy Association found that the demand for and interest in applying evidence to physical therapist practice had grown in the last decade, yet one quarter of the respondents stated that they used literature in their clinical decision making less than twice a month [8]. The authors found that training, familiarity with and confidence in search strategies, use of databases, and critical appraisal tended to be associated with younger, recently licensed therapists.

A 2003 survey by McNeil et al. provided a snapshot of the integration of information technology into the nursing education curriculum in the United States [9]. Information technology, as defined in this survey, included information literacy skills, as well as computer literacy skills and informatics competencies. The survey attempted to answer several questions, including what specific information technology and computing skills were currently being taught in the United States and to what extent faculty members are prepared to teach this knowledge and associated skills. The findings suggested that current baccalaureate programs were addressing computer literacy skills rather than information literacy skills, and the expectations for information technology skills for students entering both the undergraduate and graduate nursing programs were low. The survey also found that there were gaps in the information technology content taught at both the graduate and undergraduate level. Curriculums had evidence of skills in accessing electronic resources, but content related to evidence-based practice was less visible.

There also appeared to be a gap in the knowledge needed by nursing faculty to prepare nurses to be skilled in information technology and its use in managing clinical information in daily practice. The majority of nurse educators were primarily at the novice or advanced beginner level regarding the use of information technology tools and skills such as word processing, bibliographic retrieval, and presentation software.

These findings reinforce our conviction that a collaborative approach between health sciences librarians and educators is more effective in imparting the needed skill sets and, therefore, addressing the identified barriers to research uptake and knowledge transfer.

\section{Program description}

The Bracken Health Sciences Library at Queen's University in Kingston, Ontario has offered a curriculum-based information literacy program since the early 1990s, particularly in the School of Medicine. Curriculum-based instruction is not a new methodology for teaching information literacy skills. Wallace defined it as "a course-integrated approach to the development of skills and knowledge that is integrated into the teaching, learning and assessment or curriculum objectives and content" [10]. Provision is made for the developmental progression of skills throughout the course, unlike knowledge transmission through stand-alone or discrete subjects or through training programs offered outside the formal curriculum. Wallace argued that this approach allows students to develop the skills and knowledge that are associated with information literacy as part of the learning process itself. This integrated approach also allows information liter- acy development to occur incrementally at the same time, allowing students to transfer skills and knowledge throughout their undergraduate program. Verhey [11], Jacobs [12], and Shorten [13] all suggest some measure of success in improving the information literacy skills of nursing students.

Comprehensive course integration for nursing, occupational therapy, and physical therapy has developed and evolved in the past 3 years, largely owing to the assignment of liaison librarians to the Schools of Nursing and Rehabilitation Therapy. The Collaborative Nursing Program, established by St. Lawrence College and Queen's University, provided funding for a full-time librarian's position to support the program. For rehabilitation therapy, the new master's program offered literature-dependent courses such as "Evidence-Based Practice" and "Interpretation of Applied Research in Rehabilitation Science" - a perfect opportunity for librarian-educator collaboration.

For both schools, it was decided to integrate information literacy instruction into required courses. Librarians and faculty teaching the course established specific goals and objectives, teaching methods, and assignments for the library component of the course. These meetings ensured continuity between the skills taught by librarians and the overall course objectives.

\section{Instructional methods}

A variety of instruction methods were used and included self-directed workbooks, hands-on database searching sessions, in-class lectures and presentations, and assignments. While it would be admirable to say that the instruction methods employed were always based on the best method for ensuring optimum skill development, other practical factors, such as class size and time allotted to the course, were contributing factors. In reality, the norm was to use a variety of teaching methods.

In-class lectures, while used sparingly, were an important component of most courses. This method was most often used to introduce broad topics and provide the foundation for subsequent uses of self-directed workbooks, hands-on sessions, and assignments. Lectures generally did not include demonstrations of specific library tools such as databases and catalogues.

Workbooks served as a bridge between the presentation and the hands-on database searching sessions and were usually the first point of contact between individual students and librarians. Developed by the liaison librarians and using examples and exercises that reflected course content, the workbooks introduced concepts that required review, such as identifying citation elements, searching the library catalogue for known items, identifying MeSH and CINAHL controlled vocabulary, and evaluating Web sites according to stated criteria. Follow-along and review exercises allowed students to assess their understanding of the material provided to them. A final exercise synthesized the topics covered in the workbook. Workbooks were either included in course packs or distributed in class and were also made available on the library Web site as PDF files.

Students had the option of working independently or in pairs or groups, and it was observed that students benefited from working with others. The workbooks were done outside of class time, usually at the library, and took on average 
$2 \mathrm{~h}$ to complete. Students often requested help at the reference desk.

Public service librarians or, in one instance, the course teaching assistant, corrected the workbooks. Each took about 10 min to correct, and answer keys were used for consistency. Workbooks were not graded (other than pass or fail), but their satisfactory completion was a prerequisite to the subsequent database searching sessions.

Students were asked to complete and return (anonymously) an evaluation form regarding the format and perceived usefulness of the workbook. Feedback was generally positive. Students liked being able to complete the workbook at their convenience and found that their skills were enhanced. Typical comments were, "I liked the self-directed aspect: hands-on, but support available at library"; "took you through the necessary procedures step by step"; "built in a progressive way"; and "all new concepts!" Students liked that they were encouraged to work with others and get to know each other, since this was often their first assignment for the term or program. Negative comments reflected the absence of librarians during evenings and weekends and the length of time to complete the workbook. Some students disliked "that you had to come into the library to complete some sections", although others wrote, "I like that it got us into the library." Comments from students with previous university studies but no former bibliographic instruction seemed to indicate that library instruction was useful: 'I've been at Queen's for 2 years, but it's only now that I feel confident using the library."

Corrected workbooks were returned at the beginning of the database searching sessions, and librarians reviewed common trouble spots. Multiple sessions of a class were taught to ensure that each student had their own computer during a database training session. The Bracken Health Sciences Library is equipped with two computer labs, which double as teaching centers, consisting of 30 computers. In larger sessions with 12 or more students, a librarian instructor and a "librarian roamer" were on hand. Based on the feedback, the students appreciated having a second librarian.

Subject-specific database searching examples were integrated into the corresponding course. Each student received a copy of class notes that covered the material presented or had the course notes ahead of time in their course pack. Students were encouraged to refer to class notes to complete the assignments and to keep the notes to refer to in subsequent years and other classes.

Sessions were generally $1-2 \mathrm{~h}$ in length. Overall feedback from the sessions was positive. Typical comments were, "Now I am more comfortable searching for journal articles" and "I learn better by doing than by watching." Negative comments mostly reflected the pace of the sessions - too fast for some students or too slow for others.

\section{Assignments}

Library assignments were a critical component of the sessions and were developed in consultation with the course instructor or coordinator. The values of the assignments ranged from $5 \%$ to $30 \%$ of the overall course mark. The potential of the value of a library assignment to influence the overall course mark was an important, and at first overlooked, consideration.
Occasionally, more than one librarian marked the assignments, and there were subjective differences in awarded points. To prevent this, marking rubrics were developed, and "test" group marking sessions were held to ensure consistency in the interpretation of the marking scheme.

An increase in the number of questions received at the reference desk, e-mail and telephone queries, and one-on-one consultations with liaison librarians were clear indicators of the efforts that students put into the library assignments.

The positive outcomes of the library assignments were increased contact among public service librarians and a higher profile for the information literacy course components. Drawbacks were the time commitment in developing and marking assignments. One course, for example, enrolled 100 students, and assignments took up to $1 \mathrm{~h}$ each to mark.

\section{Program Evaluation}

Evaluation is the weakest component of the described programs. There have been some evaluative studies of curriculumbased instruction sessions for information literacy skills, and findings indicate that this method of instruction does have some positive feedback.

A study conducted by Fox et al. compared the information literacy skills of nursing school graduates before and after library instruction sessions were introduced into the curriculum. The study found that graduates who completed library instruction in nursing school read a wider selection of professional journals and participated earlier in scholarly activities than graduates who had not received library instruction [14].

A 2003 survey of Ohio State University's Occupational Therapy division graduates from 1995 to 2000 found that $26 \%$ of graduates searched MEDLINE or the Cumulative Index of Nursing and Allied Health Literature (CINAHL) at least once since graduation, and formal library instruction sessions were considered useful by $42 \%$ of the graduates [15].

Ducas and Michaud-Oystryk's study of University of Manitoba faculty members found that $41 \%$ of the health sciences faculty rated librarians' teaching as having a substantial or very substantial impact on student performance [16].

Anecdotal evidence indicates that the programs developed by the authors are beneficial to students' library research behaviors. Upper-year students asking for reference assistance often refer to earlier information literacy instruction and return to refresh or hone their skills at the time of need. The questions these students ask tend to be very specific and display knowledge of core information retrieval skills. Students will often return to meet with their liaison librarian to discuss projects in other courses. Professors have remarked to us that the information literacy efforts have improved the quality of student assignments. At Queen's, librarians with enough student contact hours can elect to participate in the University Survey of Student Assessment of Teaching (USAT) For a rehabilitation therapy foundation course, 91\% of students filled out the USAT survey. Their response to questions such as "I learned a great deal from this course" and "Overall, this is an excellent course" was the same and in some cases higher than the departmental mean. One comment was, "This course was crucial for me - I would have had to learn this somehow - I was very relieved and appreciative. I have used every bit of what was taught and it was extremely helpful." 


\section{Discussion}

While information literacy programs developed for the medical curriculum at Queen's University helped to establish a foundation for programs developed for allied health, there was a need to address differences within the disciplines of nursing and rehabilitation therapy.

Nursing and allied health disciplines pose particular challenges for evidence-based practice. Closs summarizes the reservations surrounding the evidence-based nursing movement around several misconceptions - the conflict between generalized versus individualized patient concerns, the apparent lack of recognition of individual practitioners' skills, and the "paradigmatic resistance linked to the proclaimed supremacy of the randomized controlled trial (RCT) as the source of best evidence" [17].

In developing the programs, librarians attempted to address these differences. For example, one key skill used in the Nursing 205 instruction session was developing the clinical question. In information literacy sessions for the medical students, the PICO (patient - intervention or issue - comparison outcome) model is used to help students develop clinical questions. This clinical question framework, while also used with nursing students, needed to be broadened to include other types of relevant clinical questions that could be developed by a reflective practitioner. Brown's chapter on developing the clinical question was introduced to students as a method of defining a specific clinical question [18].

Occupational therapy is a relatively new discipline, and its literature is extremely interdisciplinary in its scope. The infancy of the discipline is evident in the lack of bibliographic control. For example, the subject heading "Occupational Therapy" in the 2004 CINAHL Subject Heading List has only three more specific headings in the tree structure [19]. Because the literature for occupational therapy is still maturing, it is especially important that students and practitioners have the skills to identify available evidence. After formulating research questions for their "Interpretation of Applied Research in Rehabilitation Science" information literacy assignment, students found that a paucity of evidence often required them to either broaden their research question or use related studies in other disciplines. This is also true of physical therapy: "We already know that the literature is silent on a number of important clinical questions," wrote Guccione, and "where the literature has ripened, we should be able to draw conclusions about what interventions maybe most appropriate for particular problems in particular populations to achieve certain outcomes" [20].

Ducas and Michaud-Oystryk revealed that a large number of faculty members were unaware of librarians' teaching roles [21]. The authors advocated that librarians should make every effort to interact with faculty members and not assume an awareness of the role of librarians. Apart from meeting with individual professors to plan courses, liaison librarians also attend monthly academic council meetings and report on library activities. At Queen's University, librarians are members of the Faculty Association, which facilitated the librarians' ability to develop in their role as teachers and to participate in formal course evaluation. Librarian-faculty teaching collaboration in allied health has also led to research collaboration; librarians not only perform literature searches but also partner with faculty members on research projects. Once liaison librarians become familiar with individual faculty members' areas of teaching and research, collection development becomes much more targeted and provides another avenue for collaboration.

A culture of curriculum-based instruction is needed within the library to ensure the continued success and evolvement of instruction initiatives. There are changes in the overall work environment of a library, from the daily tasks to the overall strategic plan. The Bracken Health Sciences Library is staffed by 7 professional librarians and supported by a staff of 12 library technicians. The library serves both students and faculty within the health sciences and also has commitments to outreach services in several hospitals. Even though a subject liaison librarian develops the program and assignments, other librarians teach, mark, and answer related queries at the reference desk. All reference librarians must be thoroughly familiar with assignment expectations, a challenge when several assignments for various disciplines have looming due dates.

Adopting a method of curriculum-integrated instruction presents librarians with many additional tasks that are different from past practices. "Meanwhile, the obligatory tasks of the librarian — reference duties, collection development, etc. have not diminished in importance." Nor is there a long-term reduction in reference service due to information literacy; instead, "it appears as though instruction in bibliographic skills makes the student a more sophisticated library user, which in turn increases the student's demand for reference services" [22]. In a study that analyzed the data for 83 ARL (Association of Research Libraries) libraries over a 6-year period, each student who received bibliographic instruction increased the reference demand by two to seven questions [23]. Moreover, the reference questions and responses were more complex in nature.

We feel that contact time with students is irreplaceable, and thus we have made a conscious decision not to adopt Web-based instruction, despite current first-year class sizes of 100 students for rehabilitation therapy and 130 for nursing. Web-based course software, such as WebCT, did not seem workable for bibliographic instruction, and moving courses to a Web-based environment is even more labour-intensive [24], despite self-marking quizzes. The Internet did serve as a vehicle for communicating with students; course objectives, database session dates, assignments, and mock assignments (examples of assignment expectations) were provided on library Web pages.

As librarians take on a greater teaching role, our responsibilities are equal to other faculty: class preparation, revising, grading, and dealing with students. Because many librarians "develop their own courses and methods of evaluation", Brettle suggests "better access to research evidence and mechanisms to reduce duplication" and "sharing of resources and ideas" [25]. See "Course materials" for information about accessing course materials developed by the authors of this paper.

\section{Conclusion}

We stated that the short-term goal of these programs was to teach undergraduate and graduate students advanced search strategy skills and critical appraisal techniques. Feedback 
and assignments would seem to indicate that there was some success in transferring search strategy skills to students in these programs. We cannot say with any confidence if students maintained these skills after they completed the course. We do hope that students, at the very least, are more aware of the literature search process and that there is a need for the application of a structured approach in performing searches. We also believe the programs were valuable in allowing students to develop a relationship with the health sciences librarians and increase their comfort level in using the library and its resources.

The long-term goal of the programs, as stated at the beginning of this paper, is to graduate practitioners who not only will have the skills to practice evidence-based health care but will also participate in scholarly activities and thus contribute to the evidence base in their disciplines. Long-term research would be required to provide evidence on the success or failure of the program to address these goals. We do believe that librarians have the ability to transfer skills to students in these practices, and we suggest that current curriculum changes offer an ideal opportunity for librarians to strengthen working and professional relationships with students, as well as with faculty members.

\section{Course materials}

For additional information about the programs or for course materials, please contact the authors (P. Durando for rehabilitation therapy and $\mathrm{P}$. Oakley for nursing). The course materials for first-year rehabilitation therapy students can be accessed on the Ontario Scholars Portal Cooperative Online Repository for Information Literacy (CORIL) at https://ospace. scholarsportal.info/index.jsp. The course materials can be used "as is" or adapted for local implementation and integration with course content.

\section{Acknowledgements}

The authors wish to acknowledge the librarians at the Bracken Health Sciences Library, who taught, marked, and provided reference support for the nursing, occupational therapy, and physical therapy information literacy programs: Gillian Griffith, Sandra Halliday, Suzanne Maranda, and Anne Smithers.

\section{References}

1. College of Nurses of Ontario. Entry to practice competencies for Ontario registered nurses as of January 1, 2005 [Web site]. Toronto: College of Nurses of Ontario; 2005 [cited 13 May 2004]. Available from http://www.cno.org/docs/reg/41037_EntryPracRN2005.pdf.

2. Lall A, Klein J, Brown GT. Changing times: trials and tribulations of the move to master's entry-level education in Canada. Can J Occup Ther. 2003 Jun;70(3):152-62.

3. National Physiotherapy Advisory Group. Frequently asked questions about physiotherapy entry-level practice [Web site]. Toronto: Canadian Physiotherapy Association; 2005 [cited 5 Jun 2004]. Available from http://www.physiotherapy.ca/pdfs/NPAGFAQFinal.pdf.

4. Canadian Association of Occupational Therapists. Profile of occupational therapy in Canada. 2nd ed. Ottawa: Canadian Association of Occupational Therapists; 2002.
5. Sitzia J. Barriers to research utilization: the clinical setting and nurses themselves. Intensive Crit Care Nurs. 2002 Aug;18(4): 230-43.

6. Upton D. Attitudes towards, and knowledge of, clinical effectiveness in nurses, midwives, practice nurses and health visitors. J Adv Nurs. 1999;29(4):885-893.

7. Welch A. The challenge of evidence-based practice to occupational therapy: a literature review. J Clin Governance. 2002 Dec;10(4): 169-76.

8. Jette DU, Bacon K, Batty C, Carlson M, Ferland A, Hemingway RD, et al. Evidence-based practice: beliefs, attitudes, knowledge, and behaviors of physical therapists. Phys Ther. 2003 Sep;83(9): 786-805.

9. McNeil BJ, Elfrink VL, Bickford CJ, Pierce ST, Beyea SC, Averill $\mathrm{C}$, et al. Nursing information technology knowledge, skills, and preparation of student nurses, nursing faculty, and clinicians: a U.S. survey. J Nurs Educ. 2003 Aug;42(8):341-9.

10. Wallace MC, Shorten A, Crookes PA, McGurk C, Brewer C. Integrating information literacies into an undergraduate nursing programme. Nurse Educ Today. 1999 Feb;19(2):136-41.

11. Verhey MP. Information literacy in an undergraduate nursing curriculum: development, implementation, and evaluation. $J$ Nurs Educ. 1999 Sep;38(6):252-9.

12. Jacobs SK, Rosenfeld P, Haber J. Information literacy as the foundation for evidence-based practice in graduate nursing education: a curriculum-integrated approach. J Prof Nurs. 2003 Sep;19(5): 320-8.

13. Shorten A, Wallace MC, Crookes PA. Developing information literacy: a key to evidence-based nursing. Int Nurs Rev. 2001 Jun;48(2):86-92.

14. Fox LM, Richter JM, White NE. A multidimensional evaluation of a nursing information-literacy program. Bull Med Libr Assoc. 1996 Apr;84(2):182-90.

15. Powell CA, Case-Smith J. Information literacy skills of occupational therapy graduates: a survey of learning outcomes. $J$ Med Libr Assoc. 2003 Oct;91(4):468-77.

16. Ducas AM, Michaud-Oystryk N. Toward a new enterprise: Capitalizing on the faculty/librarian partnership. College \& Research Libraries. 2003 Jan;64(1):55-74.

17. Closs SJ, Cheater FM. Evidence for nursing practice: a clarification of the issues. $J$ Adv Nurs. 1999 Jul;30(1):10-7.

18. Brown S. Shaping the clinical question. Knowledge for health care practice a guide to using research evidence. Philadelphia: W.B. Saunders; 1999.

19. Cumulative Index to Nursing and Allied Health Literature (CINAHL). 2004 Subject Heading List. vii-1012. 2003. Glendale, Calif.: CINAHL Information Systems; 2003.

20. Guccione AA. The quest for certainty: goodbye to index cards. Phys Ther. 2003 Nov;83(11):974-5.

21. Ducas AM, Michaud-Oystryk N, op. cit.

22. Saunders ES. The effect of bibliographic instruction on the demand for reference services. Portal Libr Acad. 2003 Jan;3(1):35-9.

23. Ibid.

24. Boettcher JV, Conrad R. Faculty guide for moving teaching and learning to the Web. Mission Viego, Calif.: League for Innovation in the Community College; 1999.

25. Brettle A. Information skills training: a systematic review of the literature. Health Info Libr J. 2003;20(Suppl 1):3-9. 